\title{
TEKNIK SANGGAMA \\ DALAM TEKS PAURURAVA MANASIJA SUTRA
}

\author{
Oleh: \\ I Gede Suwantana \\ Fakultas Brahma Widya, IHDN Denpasar \\ gedesuwantana@gmail.com
}

\begin{abstract}
The text of Paururava Manasija Sutra in this work is sourced from the Dhundiraja Sastri edition published by Kamakunjalata (Varanasi: Chowkhamba Sanskrit Series Office, 1967), p. 1-27 and commented on by Jayakrsna Diksita. This text is very short, composed of 53 sutras covering techniques of sexual intercourse, timing, enjoyment, age of women invited to intercourse, and techniques for maintaining resilience. The terms used in expressing the techniques, sensations, and patterns contained within them use the spiritual terms commonly used in Yoga and Tantra, for example, the achievement of layered-level pleasures, such as jana loka, tapa loka, satya loka and others. Descriptively this work tries to elaborate in detail the technique of copulation comprehensively by using other kama texts for enrichment, such as Kamasutra, Ananga Rangga and other texts. The Paururava text lays out a good and proper copulation technique that will bring maximum sexual pleasure. Determining the type of opponent in sex is also strongly encouraged by this text so that the results achieved can reach the top.
\end{abstract}

Keywords: Paururava Manasija Sutra, Intercourse, pleasure

\begin{abstract}
Abstrak
Teks Paururava Manasija Sutra dalam karya ini adalah bersumber dari edisi Dhundiraja Sastrı yang diterbitkan oleh Kamakunjalata (Varanasi: Chowkhamba Sanskrit Series Office, 1967), pp 1-27 dan dikomentari oleh Jayakrsna Diksita. Teks ini sangat singkat, terdiri dari 53 sutra dengan melingkupi teknik melakukan hubungan seks, waktu yang tepat, capaian kenikmatan, umur wanita yang diajak bersenggama, dan teknik untuk menjaga ketahanan. Istilah-istilah yang digunakan dalam mengekspresikan teknik, sensasi, dan pola yang ada di dalamnya menggunakan istilah-istilah spiritual yang umum digunakan dalam Yoga dan Tantra, seperti misalnya, capaian kenikmatan diungkapkan bertingkat-tingkat sesuai loka, seperti jana loka, tapa loka, satya loka dan yang lainnya. Secara deskriptif karya ini mencoba menjabarkan secara rinci teknik sanggama secara komprehensif dengan menggunakan teks-teks kama lain sebagai pengayaan, seperti Kamasutra, Ananga Rangga dan teks lainnya. Teks Paururava menjabarkan bahwa teknik sanggama yang baik dan tepat akan membawa kenikmatan seksual secara maksimal. Menentukan jenis lawan dalam berhubungan seks juga sangat disarankan oleh teks ini agar hasil yang dicapai bisa mencapai puncak.
\end{abstract}

Kata kunci: Paururava Manasija Sutra, Sanggama, kenikmatan 


\section{PENDAHULUAN}

Teks diawali dengan ungkapan yang hampir mirip dan biasa digunakan dalam teks sutra lainnya, yakni dengan menyatakan kesiapan untuk memasuki pelajaran bersangkutan yang akan diberikan pada sutra-sutra selanjutnya. Disini dinyatakan: athātah paururavasam manasijasutram vyāravyāsyāmah (sekarang akan dijelaskaan tentang sesuatu yang lahir dari pikiran menurut Paururava), mirip dengan Yoga Sutra Patanjali "atha yoganusāsanam" (sekarang dimulai uraian tentang yoga). Demikian juga teks Vedanta sutra juga memulai dengan kata 'atha' (sekarang): athāto brahma jijnāsā (sekarang penyelidikan tentang Brahman). Kata 'athā' berhubungan dengan keinginan kuat untuk mengetahui apa yang akan dibahas (Iyengar, 2002: 49), khususnya dalam teks ini tentang teknik berhubungan seksual. Osho (1973: 7) menyatakan bahwa kata 'athā' kondisi pikiran kemana akan diarahkan.

Sutra pertama adalah pintu gerbang dimana ketika kita bisa melihat spketrum apa yang akan diteliti, dilihat dan dipelajari. Kemudian sutra kedua secara jelas menyebutkan siapa yang memiliki kapasitas untuk memepelajari teks ini. Tidak semua teks bisa kita pelajari karena masing-masing teks memiliki spesifikasi khusus, yang jika dipaksakan tidak saja orang yang mempelajarinya itu tidak paham, tetapi juga bisa membahayakan dirinya. Sutra dua menyebutkan:

Tacchāstraparijnāne yuvāvasthāyāh
prayojakatvāt

Karena pengetahuan dari sains ini sangat berguna pada saat muda

Teks ini diperuntukkan bagi mereka yang masih muda dan tidak cocok untuk anak-anak maupun orang tua. Masa muda, pada saat menjelang pernikahan, teks ini sangat baik diajarkan, sebab rahasia kebahagiaan sebuah hubungan laki-perempuan sangat ditentukan oleh kondisi di ranjang. Jika permainan di ranjang memusakan, maka hubungan mereka akan berjalan baik, demikian juga sebaliknya jika kurang seimbang, hubungan tersebut akan mudah retak. Pada saat muda pikiran sebagian besar orang dipenuhi oleh nafsu seksual. Inilah mengapa teks ini menyebut sebagai 'manasija', artinya 'sesuatu yang muncul dari pikiran'. Sutra 3 - 7 membicarakan masalah teknik berhubungan seks. Ada empat metode yang disarankan, yakni, ciuman, menempelkan payudara ke dada, memijat payudara dan memasukkan penis ke dalam vagina sambil memeluk tubuh perempuan dengan erat. Sutra 8-13 menguraikan tentang tingkat kebahagiaan yang diperoleh dari variasi hubungan seks, seperti misalnya meminum cairan vagina akan meraih paramananda, bila penis masuk penuh ke vagina akan meraih kebahagiaan Brahman, jika setengah penisnya masuk nikmatnya seperti berada di Indraloka, menembus liang vagina yang keset itu bahagianya melampaui kata-kata, dan jika terus-menerus penis mampu bertahan dalam vagina akan mampu melihat cahaya kesadaran tertinggi.

Sutra 14 - 20 menguraikan tentang menjaga nafsu seksual tetap membara, seperti dengan tetap memegang wilayah vagina, keterbukaan wanita dalam berhubungan seks, dan mencoba berhubungan seks berkali-kali agar wanita juga merasakan puncak kenikmatan. Sutra $21-27$ membahas mengenai bagaimana kerjasama Antara kedua pasangan dalam mencapai kenikmatan seks bersama dan berbagai hal yang diperlukan untuk menjaga hal tersebut. Sutra 28 - 30 menjelaskan tentang bagaimana merangsang perempuan agar segera dewasa secara fisik shingga siap melakukan hubungan seks. Pada jaman itu, menurut komentator, teks ini, Jayakrsna Diksita, mengatakan bahwa jaman itu, perempun setelah mengalami haid pertama kali, kurang lebih sekitar 12-14 tahun sudah layak diajak untuk berhubungan badan. Semakin kecil umurnya, semakin besar kenikmatan yang diperoleh dari hubungan tersebut.

Sutra 31 - 34 memaparkan tentang rasa, terutama srngara rasa (rasa erotis) bisa muncul melalui tahapan-tahapan hubungan seksual, seperti ciuman sambil menelan ludah sang gadis, menyentuh gigi, meraba dan memeluk erat-erat tubuhnya. Sutra 35 - 40 mengulas tentang kondisi setelah terjadinya ejakulasi, munculnya kembali gairah seks setelah ejakulasi, serta indikasi kekuatan penis mampu bertahan lama mempenetrasi vagina dalam permainan berikutnya setelah ejakulasi. Sutra ini menyebutkan bahwa pemuda yang tangguh akan kembali keperkasaannya setelah satu muhurta (kurang lebih 24 menit) setelah 
ejakulasi. Kekuatan ini akan bertahan lama jika mendapat rangsangan penuh dari kemaluan wanita yang belum tumbuh rambut atau sekitar vagina yang tidak ada rambutnya.

Sutra 41 - 47 membahas tentang waktu yang tepat berhubungan seks, sebab kenikmatan yang dimunculkan berbeda-beda sesuai dengan musimnya. Teks ini menyebutkan bulan Desember adalah yang terbaik melakukan buhungan seksual karena pada saat itu sedang musim dingin. Demikian juga pada masa musim semi sangat baik bercinta. Sementara itu, beberapa bulan lainnya, dianjurkan melakukan hubungan seks dengan ketentuan tertentu. Sutra 48 - 51 membicarakan tentang tingkat kenikmatan yang dicapai dalam melakukan hubungan seks dengan wanita. Semkian muda wanita yang diajak akan semakin nikmat rasanya. Seperti misalnya disebutkan bahwa berhubungan seks dengan wanita sekitar 18 tahun akan merasa seperti berada di tingkat Jana Loka, sementara jika bercinta dengan wanita berumur antara 14 - 15 tahun akan merasakan semua jenis kenikmatan digabung bersama.

Dua sutra terakhir 52 dan 53 menjelaskaan tentang usia tua. Oleh karena umur sudah tidak memungkinkan, maka yang dilakukan tidak lagi berhubungan dengan seksual. Kontemplasi kehadapan Yang Tertinggi menjadi sangat penting, karena sang waktu sudah memanggil untuk segera pulang. Rangkaian hidup tidak bisa dihindari. Apapun yang bisa dilakukan di masa muda akan segera ditinggalkan ketika waktunya tiba. Sutra ini menyarankan bahwa memahami kama sastra sangat penting dimasa muda sehingga dimasa tua tidak lagi memikirkan hal tersebut.

\section{PEMBAHASAN}

\section{Teknik Senggama}

Setiap teks kama sastra memberikan petunjuk tentang bagaimana melakukan hubungan seks dengan baik. Ada beberapa teks yang menjelaskannya secara detail seperti kama sutra, ananga rangga dan teks lainnya, ada juga yang mengulasnya sepintas dan lebih pada aspek lainnya, baik kesehatan maupun dimensi spiritualnya. Teks Paururava Manasija Sutra juga memberikan gambaran tentang bagaimana melakukan hubungan seks dengan baik. Tahapan dalam senggama senantiasa diawali dengan pemanasan sehingga kedua pasangan samasama terangsang dan siap melakukan hubungan seks. Tentang pemanasan, teks ini mengatakan:

Darpako dvodhane syamadharasudha prasanamaupade sikangam

(Paururava Manasija Sutra, 3)

Dalam membangitkan gairah seksual, meminum cairan nektar bibir wanita yang dicintai adalah prosedur awal dari sains ini.

Ciuman adalah langkah awal dalam melakukan hubungan seks. Teks di atas menyebut nama Darpaka, yakni nama lain dari Deva Kama, artinya Dia yang menyulut bangkitnya gairah seksual. Agar nafsu seksual bangkit (darpaka), mencium lawan jenis adalah langkah awal. Teks Kama Sutra Vatsyayana juga mengatakan bahwa mencium, memeluk serta melakukan rabaan dilakukan sebagai awalan sebelum perang ranjang dimulai. Lebih lengkapnya Kama Sutra Vatsyayana (Fosse: 2012: 77) menguraikan sebagai berikut:

It is said by some that there is no fixed time or order between the embrace, the kiss, and the pressing or scratching with the nails or fingers, but that all these things should be done generally before sexual union takes place, while striking and making the various sounds generally takes place at the time of the union.

(Kamasutra, 2.3.1)

Ciuman adalah hal yang penting, tetapi menurut teks di atas tidak ada ketentuan yang pasti karena ciuman bisa sambil melakukan pelukan serta penekanan dan elusan pada tubuh wanita. Namun walaupun demikian ini sangat pentingdilakukansebelum coitus dilangsungkan. Mengawali proses senggama, ciuman dan yang mengikutinya itu mesti dilakukan secara moderat, bisa dilakukan secara bergantian atau bersamaan sekaligus. Tidak ada aturan apakah meraba lebih dulu atau mencium. Suasana di atas ranjang sangat dominan menjadi pemicu terhadap hal ini. Apa yang dilakukan sepenuhnya menjadi keahlian Sang Perkasa agar wanita yang diajak dengan sepenuhnya memasrahkan dirinya. Ciuman bisa dilakukan sebentar atau pun panjang disesuaikan dengan situasi kedua 
pasangan.

Mengenai daerah mana saja yang dicium, teks Paururava Manasija Sutra tidak menyebutkannya secara rinci, namun satu hal yang pasti, yakni ciuman yang dilakukan akan memiliki kenikmatan yang tinggi hanya ketika sampai meminum ludah Sang perempuan. Puncak dari ciuman adalah saling bertukar ludah sebagai bentuk hubungan intim yang dalam. Kedua pasangan seolah-olah menyatu, sharing tubuh satu dengan yang lainnya. Sebagai bentuk variasi dari ciuman, Vatsyayana (Fosse: 2012: 78) mendeskripsikannya sebagai berikut: Kissing is done on the forehead, the hair, the cheek, the chest, the breasts, the lips and inside the mouth. The Lata also kiss crotch, the armpits, and the mount of Venus.

(Kamasutra, 2.3.4-5)

Ciuman pada puncaknya menurut Paururava ada di bibir dan meminum ludah masingmasing. Tetapi, bagian tubuh tertentu juga bisa dan sangat baik dicium untuk menambah gairah seksual menurut Vatsyayana, seperti pada rambut, dagu, payudara, juga leher, bahu perut dan bagian bibir vagina. Ciuman akan terasa sangat intim ketika bibir mampu masuk ke dalam mulut pasangan dan mengulum lidah, mengulum bibir bagian atas dan bawah serta gigi. Ciuman dengan mengulum bagian dalam mulut inilah yang paling dalam yang memungkinkan terjadinya pertukaran air liur. Ciuman bibir menurut teks Ananga Ranga (Burton, 2001: 35-36) jenisnya ada 10, sebagai berikut:

First: Nlita-kissing, which means "mishrita", mixing or reconciling. If the wife be angry, no matter however little, she will not kiss the face of her husband; the latter then should forcibly fix his lips upon hers and keep both mouths united till her ill-temper passes away.

Ciuman Nlita, yakni ciuman campuran atau saling menyatukan. Dalam teks Ananga Ranga proses hubungan seks disebutkan sebagai suami istri. Terkadang istri tidak langsung mau diajak diuman. Di awal dia sedikit menolak, tampak seperti marah. Tetapi, menurut teks ini disarankan agar jangan berhenti, tetap lakukan dan agak paksa sedikit agar bibir istri tetap berada dalam kuluman suami. Meskipun awalnya istri agak melawan, tetapi lanjutkan saja sehingga secara perlahan istri akan mengurangi perlawanannya dan mulai memberikan kesempatan untuk itu. Marahnya akan hilang bersamaan dengan kesediaan menerima ciuman suaminya dan bersiap-siap untuk membalasnya.

Second: Sphurita-kissing, which is connected with twitching and vellication. The wife should approach her mouth to that of her husband, who then kisses her lower lip, whilst she draws it aways, jerking, as it were, without any return of osculation.

Ciuman jenis kedua disebut dengan Sphurita, yakni sebuah ciuman yang didahului oleh istri. Sang istri mendekatkan bibirnya kepada bibir suaminya dan kemudian mencium bibir bagian bawah. Istri melakukannya ini berali-kali dan suami hanya tenang membiarkan kondisi ini berjalan beberapa saat.

Third: Ghatika, or neck-nape kissing, a term frequently used by the poets. This is done by the wife, who, excited with passion, covers her husband's eyes with her hands, and closing her own eyes, thrusts her tongue into his mouth, moving it to and fro with a motion so pleasant and slow that it at once suggests another and higher form of enjoyment.

Ciuman Ghatika dilakukan oleh istri kepada suaminya. Istri dengan penuh bergairah mencium leher suaminya, menutup wajah suami dengan kedua telapak tangannya, kemudian memejamkan mata merasakan sentuhan bibirnya. Istri merasakan desakan kehangatan oleh karena birahinya perlahan bangkit dengan sesekali menelan ludah. Pada kondisi ini istri telah siap untuk melanjutkan hubungannya lebih lanjut. Istri telah mendapatkan kesatuan kimiawi tubuhnya dengan suami dan siap sharing bersama suaminya.

Forth: Tiryak, or oblique kissing. In this form the husband, standing behind or at the side of his wife, places his hand beneath her chin, catches hold of it and raises it, until he has made her face look up to the sky;' then he takes her lower lip beneath his teeth, gently biting and chewing it. 
Ciuman Tiryak dilakukan oleh suami dengan cara berdiri di sebelah atau belakang istri. Sang suami memeluk leher si istri dengan kelembutan dan kehangatan. Suami menarik dagu istrinya ke atas sampai mukanya menengadah ke atas. Suami kemudian menurunkan wajahnya ke wajah istri dan mulai mengulum bibir bagian bawahnya dengan lembut. Secara perlahan bermain dengan gigi, mulai menggigit bibir dan lidah istri serta mengulum. Istri akan merasakan sensasi seksual yang luar biasa. Istri sangat merasa dekat dengan suaminya ketika secara penuh dicium seperti ini. Kedekatan yang tidak bisa diungkapkan dengan kata-kata dirasakan dan istri siap untuk melakukan apapun yang diminta suaminya di atas ranjang.

Fifth: Uttaroshtha, or "upper-lip kissing". When the wife is full of desire, she should take her husband's lower lip between her teeth, chewing and biting it gently; whilst he does the same to her upper lip. In this way both excite themselves to the height of passion.

Saat sang istri mengulum bibir bagian bawah suami dan suami mengulum bibir bagian atas istri disebut dengan ciuman Uttaroshtha. Saat ini baik istri maupun suami sama-sama aktif. Istri penuh dengan gairah menggigit bibir bagian bawah suaminya, demikian juga suami mengulum dan mengigit bagian atas bibir istrinya. Dengan ini keduanya semakin meningkat birahinya dan siap untuk melakukan perjuangan berikutnya. Pada saat ini kemungkinan pertukaran cairan antara keduanya terjadi.

Sixth: Pindita, or "lump-kissing". The wife takes hold of her husband's lips with her fingers, passes her tongue over them and bites them.

Dengan ciuman Pindita ini, kemungkinan terjadi pertukaran cairan bibir paling besar. Sang istri, yang telah membara, yang nafasnya mulai tidak teratur penuh birahi, memegang wajah atau bibir suaminya, mendekatkan bibir ke mulutnya, memasukkan bibir sendiri dan mengulum lidah suaminya dengan bersemangat. Sesekali istri atau suami menggigit lidah masingmasing dan kemudian saling kulum bergantian. Kondisi tubuh telah semakin hangat dengan nafsu semakin membara.
Seventh: Samputa, or "casket-kissing". In this form the husband kisses the inside mouth of his wife, whilst she does the same to him.

Ketika sang suami mengulum sepenuhnya bagian dalam mulut istri, demikian juga istri mengulum bagian dalam mulut suaminya, ini disebut dengan ciuman Samputa. Pada saat ini penyatuan kedua pasangan ini sangat intim. Melalui sensasi di dalamnya, istri dan suami masing-masing saling menyelami dan merasakan kehangatan. Istri merasakan bahwa suaminya adalah segala-galanya. Istri akan merasa sangat membutuhkan suaminya. Demikian juga sebaliknya suami merasakan bahwa istrinya adalah bagian dari dirinya yang sangat didambakannya. Perasaan kesatuan dua tubuh bisa dirasakan dalam situasi ini.

Eight: Hanuvatra-kissing. In this mode the kiss should not be given at once, but begin with moving the lips towards one another in an irritating way, with freaks, pranks, and frolics. After toying together for some time, the mouths should be advanced, and the kiss exchanged.

Hanuvatra adalah jenis ciuman yang agak keras. Cocok bagi mereka yang suka hubungan seks dengan cara agak kasar. Ciuman ini dilakukan dengan mengulum bibir masingmasing dengan cara agak kasar seolah-olah nafsu untuk bersenggama meledak-ledak. Disini ciuman bisa saling gigit saling sedot sampai betul-betul terasa dan sensasinya tidak biasa. Ini dilakukan oleh orang khusus yang memang biasa dan menikmati melakukan hal tersebut. Sebagian besar orang melakukan ciuman dengan cara lembut, saling menukar cairan dan merasakan kehangatan masing-masing. Tetapi ada juga orang yang suka agak kasar mainnya sehingga seolah-olah bertengkar, namun sesungguhnya saling menikmati.

Ninth: Pratibodha, or "awakening kiss". When the husband, who has been absent for some time, returns home and finds his wife sleeping upon the carpet in a solitary bedroom, he fixes his lips upon hers, gradually increasing the pressure until such time as she awakes. This is by far the most agreeable form of osculation, and it leaves the most pleasant of memories. 
Ada jenis ciuman kangen yang biasanya dilakukan karena lama tidak bertemu. Ciuman Pratibodha menggambarkan seorang suami yang lama meninggalkan istrinya kemudian datang pada saat istrinya tidur, mungkin di malam hari atau pada saat istrinya tidur siang di kamar sendirian. Baru datang, suami tidak memanggilnya, melainkan langsung menciumnya dengan menempelkan bibir ke bibir istrinya, semakin lama ciumannya semakin dalam sampai istrinya terbangun. Ini adalah jenis ciuman yang paling hangat, paling dirindukan oleh pasangan. Istri ketika bangun mendapati suaminya telah datang dan sedang menciumnya penuh mesra. Ini adalah sejenis kejutan buat istri yang lama ditinggalkan.

Tenth: Samaushtha-kissing. This is done by the wife taking the mouth and lips of the husband into hers, pressing them with her tongue, and dancing about him as she does so.

Ciuman yang dimulai oleh sang istri mendekatkan mulut dan bibir suami ke bibirnya, mengulum lidah suaminya dan menari sesuai keinginannya. Ini disebut dengan ciuman samaushtha, yakni ciuman dan menari bersamaan. Ciuman ini sangat romantis dilakukan oleh pasangan untuk menikmati keindahan hari yang penuh gairah. Sensasi yang ditimbulkan rasa nikmat yang dapat melenyapkan semua beban hidup untuk sementara waktu. Sementara itu, Vatsyayana (Fosse: 2012: 79) melihat bahwa ciuman yang dilakukan oleh perempuan terbagi menjadi tiga. Beliau menguraikannya sebagai berikut:

For instance, a young women has three kinds of kiss: the measured, the throbbing, and brushing.

(Kamasutra, 2.3.7)

Seorang wanita dengan agak terpaksa memberikan bibirnya dicium, namun dia tidak bereaksi, tidak membalas ciuman itu secara aktif, disebut dengan ciuman measured. Dia menikmati ciuman itu secara pasif, menerima apapun yang dilakukan oleh laki-laki pasangannya dengan pasrah. Biasanya ciuman ini dilakukan oleh perempuan yang masih malumalu atau mereka yang masih belum berpengalaman di dalam berhubungan dengan laki-laki. Dia menyerahkan begitu saja bibirnya untuk dilumat oleh pasangannya sambil menikmatinya. Seorang wanita menikmati ciuman dengan sesekali menggerakkan bibir bagian bawahnya ketika dikulum oleh pasangannya termasuk ciuman throbbing. Oleh karena sensasi erotis yang dirasakannya, wanita ini secara spontan menggerak-gerakkan bibirnya, memberikan uang bagi pasangannya untuk menciumnya lebih dalam. Dia tidak mampu melakukan gerakan bibir yang lebih dari itu.

Sementara itu, ketika wanita mencium pasangannya secara aktif, memutar dan mengulum bibir laki-lakinya, merasakan kenikmatan yang ditimbulkan sambil memejamkan mata dan menaruh telapak tangan di mukanya, dan lidahnya juga secara aktif melumat lidah lawannya dengan lembut disebut dengan ciuman brushing. Ciuman ini biasanya dilakukan oleh wanita yang telah berpengalaman melakukan hubungan seksual. Saat melakukan ini, wanita merasa sangat nyaman dan menikmati serta gairahnya bangkit dengan segera. Wanita yang skill seksnya tinggi akan sangat cepat terbangkitkan gairahnya dengan cara ciuman seperti ini. Setelah ini sang wanita akan siap untuk diajak eksplorasi seks lebih dalam, sampai pada puncaknya, yakni terjadi penetrasi penis ke liang vaginanya yang telah siap sejak awal.

Setelah ciuman dilakukan, ketika nafsu seks telah mulai bangkit dan keinginan untuk sharing kebahagiaan semakin kuat, perlu dilakukan tahapan berikutnya yang membuat kedua tubuh semakin menyatu. Hubungan seks yang baik adalah ketika kedua tubuh berada dalam kondisi yang setara tidak hanya dalam birahi, tetapi juga seirama dalam rasa dan spirit. Hubungan seks yang terjadi kemudian hanyalah sebuah sharing mengenai berbagai aspek, tidak hanya fisik, tetapi mental dan spiritual. Paururava Manasija Sutra mengatakan bahwa teknik berikutnya setelah ciuman adalah mendekatkan payudara perempuan ke dada sampai terasa ada tekanan.

Urasi kucābhyām samslesanam dvitiya mangam

(Paururava Manasija Sutra, 5)

Menekan kedua payudara perempuan ke dada adalah aktivitas kedua dalam cinta seksual. 
Untuk bisa melakukan senggama ke tingkat yang lebih lanjut, langkah awal adalah ciuman. Ketika mencium bibir seorang wanita sukses dikerjakan, maka menjelajahi bagian tubuhnya yang lebih intim akan terbuka. Bagian intim tubuh wanita yang paling luar dan yang bisa diajdikan indikasi dia itu bisa diajak melakukan senggama adalah bibir. Bila bibirnya telah mampu dikuasai, apalagi sampai menelan ludahnya, maka intim tubuh perempuan berikutnya akan segera bisa dikuasai. Laki-laki tidak bisa langsung memegang tubuh intim yang lebih dalam dari seorang wanita. Diperlukan sebuah tahapan sehingga akhirnya wanita bisa tunduk dan mengikuti apapun yang hendak lakilaki lakukan di atas ranjang.

Saat nafas wanita sudah mulai tidak beraturan sebagai akibat ciuman yang mendalam dlam beberapa waktu, bersamaan dengan tumbuhnya gairah seksualnya, wanita akan memberikan peluang untuk memegang payudaranya. Tidak hanya memegang dan meremasnya, bahkan mendekatkannya ke dalam tubuh laki-laki pun diperkenankan. Wanita yang telah berkenan untuk dimainkan payudaranya akan membiarkannya menempel dan ditekan di dalam dada laki-laki. Dia akan erasakan kehangatan dan kenikmatan yang lebih ketika susunya melekat dekat dengan tubuh laki-laki hangat dan perkasa, apalagi kegiatan menciumi bibirnya masih tetap dilakukan.

Dalam Kama Sutra Vatsyayana menekan payudara ke dada mungkin bisa disejajarkan dengan teknik pelukan. Dalam sebuah teknik pelukan, menekan payudara sampai tertekan dengan dada dan bahkan membiarkan payudaranya bersandar di dada adalah cara mudah membangkitkan gairah perempuan. Vatsyayana mengatakan sebagai berikut:

Menekan payudara wanita dengan dada dan membiarkan dia mentransfer berat badannya dan bertumpu di dada. Inilah pelukan payudara.

(Kamasutra, 2.2.25).

Perlakuan seperti ini kepada wanita akan membrikan kesempatan baginya untuk memanjakan dirinya dan menyerahkan tubuhnya kepada laki-laki. Dalam sebuah senggama, kesiapan wanita untuk menyerahkan tubuhnya secara utuh sangat penting jika ingin kualitas senggama itu berjalan baik. Dengan membuat wanita nyaman menempelkan bagian erotisnya kepada laki-laki, itu berarti perempuan telah membuka hati dan siap untuk berbagi rasa. Tanpa ini, wanita biasanya sangat melindungi tubuh, terutama bagian sensitifnya. Mungkin wanita, oleh karena tabiatnya ingin memamerkan lekukan tubuhnya untuk menarik lawan jenis, tetapi agar dia siap menyerahkan bagian intim tubuhnya itu sangat sulit. Berbagai proses harus dilakukan terlebih dahulu. Disini, ketika payudaranya sudah dikuasai dan bisa menempel di dada, apalagi dia dengan penuh kesadaran menindihkannya ke dada, artinya dia siap melanjutkannya sampai puncak.

Setelah melekatkan payudara wanita sambil mendekap dan menciumnya, maka dilanjutkan dengan meremasnya dengan lembut. Pijatan lembut pada payudara akan membuat wanita semakin cepat terangsang. Bahkan rangsangannya akan mampu mencapai puncak sehingga tidak tahan lagi untuk segera mempenetrasi lingga ke dalam yoninya sendiri. Kulit payudara sangat sensitive dan memiliki syaraf yang ketika diraba mampu membangkitkan gairah seksual yang menggebu. Siapapun wanita, ketika dia telah luluh sampai memberikan meremas susunya, tahapan berikutnya yang paling intim tidak bisa dia tolak. Membuka pintu terakhir yang paling rahasia segera akan dilakukan. Teks Paururava Manasija Sutra menyatakan:

$\begin{array}{ll}\text { Dosbhyām } & \text { kucayorupamardanam } \\ \text { tretiyamangam } & \end{array}$
(Paururava Mansija Sutra, 6)

Memijat kedua payudaranya dengan tangan adalah prosedur ketiga.

Rupanya, teks Paururava Manasija Sutra menekankan pentingya bermain dengan payudara jika ingin kepuasan seksual diraih. Berbeda dengan Vatsyayana, bermain dengan payudara adalah bagian integral dari semua proses yang ada, apakah dari mulai memeluk, kemudian mencium, menekan dengan kuku, membuat tanda maupun pada saatmenancapkan lingga ke yoninya. Menurutnya, saat pelukan, ketika tubuh menjadi sangat dekat, payudara wanita akan secara otomatis ditekan ke tubuh laki-laki. Demikain juga pada saat ciuman, salah satu bagian tubuh wanita yang dianjurkan untuk dicium adalah payudaranya. Demikian juga pada 
saat melakukan rabaan, bagian tubuh yang paling sensitif untuk diraba sebelum bagian dalam pahanya adalah payudara. Saat menggigit dan menggoreskan kuku pun, bagian payudara akan sangat menarik untuk digigit dan digores untuk membuat sebuah tanda merahyang akan tetap nampak selama beberapa hari. Saat coitus, payudara juga masih dianjurkan untuk tetap dipegang dan diremas agar panas atau nafsu birahi tetap bertahan lama dan ereksi tetap bisa berlanjut.

Didalam teks Kamasutra tidak diulas secara khusus dalam sebuah bab karena bermain dengan payudara adalah bagian menyeluruh dari adegan senggama. Sementara itu, Paururava Manasija Sutra menyebutkan, dari empat tahapan teknik hubungan seksual, dua diantaranya membahas tentang prmainan di payudara. Ini berarti, bermain di area payudara adalah sangat penting dan vital di dalam berhubungan seks. Bisa dikatakan memainkan payudara adalah sebuah senggama minor, artinya ini adalah jembatan menuju senggama yang sesungguhnya.

Teknik terakhir setelah memijat dan menstimuli payudara, teks Paururava Manasija Sutra menganjurkan agar lingga yang telah tegang dank eras sejak awal pemanasan, segera dimasukkan ke liang yoni wanita yang telah siap. Jika payudara sudah bisa dikuasai, maka bagian yang lebih intim lagi bagi seorang wanita adalah selangkangan. Jika laki-laki kurang mahir dalam memenangkan pertandingan di kasur, biasanya ia gagal sampai membuka selangkangan wanita itu, sebab biasanya wanita sangat memproteksi bagian paling intimnya tersebut dari godaan siapapun. Hal ini dilakukan oleh karena berbagai factor, seperti masalah moral, ketidaknyamanan, dan perasaan bersalah. Namun, jika laki-laki telah mampu membangkitkan gairah wanita melalui ciuman dan rabaan di payudara, tetapi masih membiarkan wanita itu berpikir, dipastikan selangkangannya sulit untuk dibuka. Bahkan pikiran itu pun akan bisa mendinginkan kembali gairahnya sehingga coitus batal. Oleh karena itu, penting sekali ketika gairah wanita sudah mencapai puncak, agar pikirannya tidak lagi bekerja. Laki-laki harus mampu membuat perasaannya bermain, sehingga nafsunya yang sudah tumbuh tersebut dibuat semakin membara. Saat wanita itu lengah dan larut di dalam perasaannya, secara perlahan, selangkangannya bisa dibuka lebar. Teks ini mengatakan:

\section{Jatukāstha vatsamslesanam turiya mangam \\ (Paururava Manasija Sutra, 7).}

Pelukan intim, seperti kelelawar merekat pada kayu, adalah prosedur keempat.

Pelukan intim yang dimaksudkan disini adalah ketika lingga telah masuk ke dalam liang di antara selangkangan wanita. Saat selangkangan bisa dibuka, maka bermain-main diarea ini sebelum menancapkan lingga ke dalamnya sangat penting untuk membuat si wanita itu merasa nyaman dan dihargai. Ketika dirasa cukup, dimana pihak wanita memberi kode agar segera mengakhiri petualangan, maka laki-laki harus segera berinisiatif untuk membuat formasi atau gaya agar lingga dengan aman dan nyaman memasuki liang yoninya. Walaupun yoninya telah terbuka, lebar penting sekali tetap memperhatikan agar liangnya tidak sampai terkoyak dan merasakan kesakitan. Biarkan wanita saat itu merasakan sedikit agak dipaksa dan kemudian merasakan kenikmatan yang lebih, sehingga dia tetap maksimal dalam senggama.

Senggama dalam teks Paururava Manasija Sutra sebaiknya dilakukan dengan jalan berpegangan erat pada tubuh wanita seperti hanya kelelawar di dahan kayu. Hal ini dilakukan adalah untuk membangun kehangatan dan transfer energy dari satu dengan yang lainnya. Hubungan seks adalah sharing energi sehingga dengan coitus sambil memeluk erat pasangan sangat disarankan. Dengan ini wanita akan dengan cepat merasakan kepuasan. Hubungan seks yang baik adalah ketika kedua pasangan mendapatkan kepuasan. Dalam Kama sutra Vatsyayana menjelaskan bahwa wanita harus mendapatkan klimaks terlebih dahulu dibandingkan laki-laki.

Jāterabhedādhyampatyoh $\quad$ sadresam
sukamisyate
$\begin{aligned} & \text { Tasmāttayopacarya stri } \\ & \text { prāpnuyātdatim }\end{aligned}$

(Kamasutra, 2.130 )

Because the couple does not belong to different species, they achieve a similar 
satisfaction. Therefore a women should be treated in such a way that she reaches the ectasy first.

Karena pasangan itu bukan dari spesies yang berbeda, mereka akan mencapai kepuasan yang sama. Oleh karena itu, seorang wanita harus diperlakukan sedemikian rupa sehingga dia mampu mencapai ekstasi (orgasme) duluan.

Teks mengatakan bahwa wanita harus mencapai orgasme terlebih dahulu dalam sebuah hubungan seks. Alasannya adalah, lakilaki setelah mencapai orgasme dan ejakulasi akan sulit atau mustahil untuk tetap melanjutkan penetrasi lingganya ke dalam liang vagina. Dalam kondisi ini, jika wanita belum mencapai puncak, wanita akan tiba-tiba diberhentikan kenikmatannya yang sedang dalam proses, sehingga dirinya akan merasa kecewa atau gagal. Ini adalah seperti bola yang dilempar ke atas, tidak mampu mencapai momentum tertinggi oleh karena tiba-tiba ada halangan yang membuatnya segera kembali ke lantai.

Lalu bagaimana jika wanita yang mencapai orgasme duluan? Walaupun wanita telah merasakan sensasi puncak dari senggama, dia akan masih mampu menikmati hubungan setelah itu dan mampu melayani sodokan lingga dari pihak lawannya hingga akhirnya lawannya itu mencapai klimaks. Bahkan tidak sedikit wanita menikmati hubungan seks dengan mendapatkan orgasme berulang-ulang. Setelah mencapai puncak, wanita masih tetap bisa merasakan kenikmatan seks sampai mencapai klimaks pada sesi berikutnya dan berikutnya.

Kenikmatan seksual bisa di dapat apakah secara maksimal (utama), sedang (madya), atau tidak memuaskan (kanista) menurut Ananga Ranga disesuaikan dengan tipe pasangan itu sendiri. Jika pasangan itu dalam satu tipe, maka mereka akan merasakan kepuasan maksimal, demikian juga jika tidak satu tipe akan kurang memuaskan. Ini harus diketahui oleh setiap orang sehingga ketika mereka memutuskan untuk melakukan hubungan seksual dalam kurun waktu yang lama atau sepanjang hayat (seperti suami-istri), mereka sudah menemukan pasangannya yang tepat. Ananga ranga (Burton, 2001: 12-14) menyebut ada tiga tipe laki-laki sebagai berikut:
There are three kinds of men, namely, the Shasha, or the Hare-man; the Vrishabha, or Bull-man, and the Ashwa, or Horseman.

Ada tiga jenis laki-laki menurut panjang kelaminnya, yakni Shasha (kelinci), Vrishabha (kerbau), dan Ashwa (kuda).

Menurut teks Ananga Ranga, berdasarkan ukuran panjang penisnya ketika ereksi dibedakan menjai tiga yakni, laki-laki kelinci, kerbau dan kuda. Setiap laki-laki ukuran kelaminnya tidak sama, baik secara perorangan dalam sebuah lingkungan maupun rata-rata dalam satu bangsa atau Negara. Namun kecenderungan sebuah bangsa memiliki dominan tertentu, artinya dalam sebuah bangsa ada yang tipe kelinci jumlahnya dominan, juga pada bangsa lain kemungkinan tipe kerbau dominan, demikian juga yang lainnya. Seperti misalnya, rata-rata ukuran panjang penis orang Arab lebih panjang dibandingkan dengan orang Asia Timur. Walaupun demikian bukan berarti di Arab tidak ada yang memiliki penis ukuran pendek, hanya saja secara rata-rata mereka memiliki ukuran yang lebih panjang, bisa kerbau atau kuda.

The Shasha is known by a Linga which in erection does not exceed six fingerbreaths, or about three inches. His figure is short and spare, but well-proportioned in shape and make; he has small hands, knees, feet, loins and thighs, the latter being darker than the rest of the skin. His features are clear and well proportioned; his face is round, his teeth are short and fine, his hair is silky, and his eyes are large and well-opened. $\mathrm{He}$ is of a quiet disposition; he does good for virtue's sake; he looks forward to making a name; he is humble in demeanour; his appetite for food is small, and he is moderate in carnal desires. Finally, there is nothing offensive in his Kama-salila or semen.

Laki-laki shasha memiliki panjang Linga waktu ereksi kurang lebih 6 jari atau 3 inci. Orang ini tubuhnya pendek tapi penampilannya menawan. Dia memiliki tangan, kaki, lutut, dan pantat kecil. Penampilannya jelas dan sangat 
proporsional. Mukanya bundar, giginya pendek dan bagus, rambutnya agak pirang, matanya besar dan terbuka dengan baik. Orangnya pendiam, dia melakukan hal yang baik demi kemuliannya, dia melihat ke depan untuk memperoleh nama, dia orangnya sopan, ukuran makannya sedikit, dan sangat moderat dalam nafsu binatang. Terakhir, tidak ada yang offensive pada kamanya (salila - semen).

Ciri-ciri umum dari orang tipe shasha adalah perawakannya tidak begitu besar namun proporsional. Bagian-bagian tubuhnya seperti tangan, kaki, pantat dan yang lainnya juga kecil, termasuk giginya. Dengan melihat penampilan seperti ini, seorang wanita walaupun tidak melihat penisnya secara langsung, akan dapat memprediksi bahwa ukuran panjang kelaminnya tidak lebih dari 3 inci. Maka dari itu, wanita yang tidak satu tipe dengan laki-laki seperti ini harus menghindarinya agar nanti dalam hubungan lebih lanjut tidak buruk.

The Vrishabha is known by a Linga of nine fingers in length, or four inches and a half. His body is robust and tough, like that of a tortoise; his chest is fleshy, his belly is hard, and the frogs of the upper arms are turned so as to be brought in front. His forehead is high, his eyes large and long, with pink corners, and the palm of his hands are red. His disposition is cruel and violent, restless and irascible, and his Kama-salila is every ready.

Laki-laki Vrishabha dikenatui ukuran Linga-nya 9 jari, atau kurang lebih 4,5 inci. Badannya kekar dan kuat, seperti kura-kura, dadanya berdaging, perutnya keras, lengan bagian atas juga besar. Dahinya tinggi, matanya besar dan panjang dengan sudut warna pink, telapak tangannya berwarna merah. Perangainya kasar, menyeramkan dan menakutkan, dan kamanya setiap saat siap.

Tipe laki-laki kerbau sangat kentara dari perangainya yang galak, tampak kasar dan menyeramkan. Tubuhnya besar dan kekar, matanya besar dan mendelik, perutnya sangat keras. Jika melihat ciri-ciri seperti ini dipastikan orang ini memiliki ukuran penis sekitar 4,5 inci. Bagi wanita yang satu tipe dengan orang seperti ini akan sangat baik didekati dan diajak kencan sebab orang ini sangat memberikan kepuasan dalam urusan ranjang. Demikian juga sangat bagus bagi mereka yang ingin melangsungkan perkawinan. Perangainya tampak menakutkan tetapi mungkin hatinya tidak. Perangai mungkin tidak selamanya menunjukkan hatinya. Banyak orang yang harinya lembut tetapi perangainya kasar, demikian juga tidak sedikti orang yang perangainya lembut tetapi sangat kasar.

The Ashwa is known by a Linga of twelve fingers, or about six inches long. He is tall and large-framed, but not fleshy, and his delight is in big and robust women, never in those of delicate form. His body is hard as iron, his chest is broad, full, and muscular; his body below the hips is long, and the same is the case with his mouth and teeth, his neck and ears; whilst his hands and fingers are remarkably so. His knees are somewhat crooked, and this distortion may also be observed in the nails of his toes. His hair is long, coarse and thick. His look is fixed and hard, without changing form, and his voice is deep. He is reckless in spirit, passionate and covetous, gluttonous, volatile, lazy, and full of sleep. He walks slowly, placing one foot in front of the other. He cares little for the venereal rite, except when the spasm approaches. His Kama-salila is copious, salt, and goat-like.

Tipe kuda diketahui memiliki panjang linga 12 jari atau sekitar 6 inci. Orang ini tinggi dan besar, tetapi tidak berotot, bentuk tubuhnya tidak terlalu manis, badannya keras seperti besi, dadanya lebar, penuh dan berotot, badan dibawah pinggang panjang, dan sama juga pada mulut dan giginya, leher dan telinganya, sementara tangan dan jarinya demikian juga. Lututnya tidak mulus, juga tampak pada kuku jari kakinya. Rambutnya panjang, lebat dan tebal. Pandangannya kuat dan tajam tanpa mengubah bentuk, dan suaranya dalam. Dia kurang dalam spirit, kurang sabar, malas dan suka tidur. Dia berjalan lambat, meletakkan kaki di 
depan orang lain. Kama orang ini kental, asin, dan seperti kambing.

Ada juga orang yang perawakannya tinggi, tubuhnya keras, dadanya lebar dan berotot, mulutnya besar dan giginya panjang, lehernya juga panjang. Orang ini agak malas dan suka tidur, rambutnya tebal dan jalannya lambat. Jika orang dengan ciri-ciri seperti ini dipastikan memiliki ukuran penis yang panjang sekitar 6 inci. Orang dengan panjang penis seperti ini memerlukan liang vagina yang agak dalam sehingga perempuan yang diajak berhubungan merasa nyaman. Jika orang tipe kuda ini berhubungan seks dengan wanita yang liang vaginanya pendek akan sangat menyakitkan bagi wanita. Hubungan ini tidak bisa diteruskan sebab akan menimbulkan trauma bagi perempuan.

Maka dari itu, diperlukan pasangan yang tepat antara laki dan wanita sehingga hubungan mereka mampu mencapai klimaks yang memuaskan diantara keduanya. Untuk melihat bagaimana kecocokan antara laki dan wanita, teks Ananga Ranga (Burton, 2001: 12-14) juga memberikan uraian tentang tipe perempuan. Seperti halnya laki-laki, perempuan juga dibagi menjadi tiga berdasarkan panjang liang vaginanya. Setiap wanita memiliki panjang yang berbeda sehingga kenyamanan untuk untuk berhubungan seksual harus disesuikan dengan itu. Adapun ketiga jenis atau tipe wanita itu adalah sebagai berikut:

Women, may be subdivided into three kinds, according to the depth and extent of the Yoni. These are the Mrigi, also called Harini, the Deer-woman; the Vadava or Ashvini, Mare-woman; and the Karini, or Elephant-woman.

Perempuan, mungkin dibagi menjadi tiga jenis, berdasarkan pada kedalaman dan keluasan Yoni. Mereka adalah Mrigi atau Harini (perempuan kijang), Vadava atau Ashvini (kuda Betina), dan Karini (perempuan gajah).

Seperti halnya laki-laki, wanita juga dibagi menjadi tiga jenis berdasarkan panjang Yoninya, yakni tipe kijang, kuda betina dan gajah. Ketiga jenis ini harus bersesuaian dengan ketiga jenis atau tipe laki-laki agar hubungan seks dapat mencapai kepuasan maksimal. Jika tidak, maka hubungan sekssual akan terganggu dan tidak mampu membuat kedua belah pihak bahagia. Kunci dari kesuksesan hubungan seksual diawal terletak pada kemampuannya untuk menemukan pasangan yang tepat. Orang akan dapat memprediksi apakah kehidupan seksual sebuah pasangan akan berjalan baik atau tidak tergantung dari kecocokan diantara mereka.

The Mrigi has a Yoni six fingers deep. Her body is delicate, with girlish aspect, soft and tender. Her head is small and wellproportioned; her bosom stands up well; her stomach is thin and drawn in; her thighs and Mons Veneris are fleshy, and her build below the hips is solid, whilst her arms from the shoulder downwards are large and rounded. Her hair is thick and curly; her eyes are black as the dark lotusflower; her nostrils are fine; her cheeks and cars are large; her hands, feet, and lower lip are ruddy, and her fingers are straight. Her voice is that of the Kokila bird, and her gait the rolling of the elephant. She eats moderately, but is much addicted to the pleasure of love; she is affectionate but jealous, and she is active in mind when not subdued by her passions. Her Kama-salila has the pleasant perfume of the lotus-flower.

Mrigi memiliki kedalaman Yoni sekitar 6 jari. Badannya manis, feminis, lembut dan ayu. Kepalanya kecil dan proporsinya bagus, dadanya tegak bagus, perutnya tipis dan kecil, pantat dan bokongnya berisi dan bangunan tubuhnya dibawah pinggang solid, lengan dari pundaknya lebar dan bundar. Rambutnya tebal. Matanya hitam seperti lotus hitam, hidungnya bagus, dagunya besar, tangan, kaki dan bibir bagian bawahnya agak kasar, dan jarinya lurus. Suaranya seperti burung kokila. Dia makan moderat, tapi sangat adiktif dengan kenikmatan cinta, dia penuh kasih tetapi pencemburu, dan pikirannya aktif, ketika tidak puas atas apa yang diinginkannya. Kama (salila) memiliki bau yang menyenangkan semerbak bunga lotus. 
Jika wanita memiliki ciri-ciri seperti disebutkan di atas, perawakannya kecil, tampak feminis, ayu, rambut tebal, bibir bagian bawah lebih besar, bokongnya berisi, warna matanya hitam bening dan jari-jarinya lurus, maka dipastikan wanita ini memiliki panjang liang vagina sekitar 6 jari. Orang ini biasanya tidak begitu bernafsu untuk makan, tetapi sangat menikmati keindahan cinta. Tipe wanita ini sangat suka bercinta dan bisa larut dalam cinta.

The Vadava or Ashvini numbers nine fingers depth. Her body is delicate; her arms are thick from the shoulders downwards; her breasts and hips are broad and fleshy, and her umbilical region is high-raised, but without protuberant stomach. Her hands and feet are red like flowers, and well-proportioned. Her head slopes forwards and is covered with long and straight hair; her forehead is retreating; her neck is long and much bent; her throat, eyes, and mouth are broad, and her eyes are like the petals of the dark lotus. She has a graceful walk, and she loves sleep and good living. Though choleric and versatile, she is affectionate to her husband; she does not easily arrive at the venereal spasm, and her Kama-salila is perfumed like the lotus.

Ashvini memiliki yoni dengan kedalaman sekitar 9 jari. Badannya menawan, lengannya tebal dari bahu ke bawah, payudara dan bokongnya berisi, dan bagian pusarnya naik tetapi tanpa perut buncit. Tangan dan kakinya merah seperti bunga dan proporsional, kepalanya miring ke depan dan dipenuhi oleh rambut yang lurus. Dahinya agak mundur ke belakang, lehernya panjang dan kebanyakan bengkok, kerongkongan, mata, dan mulutnya luas, dan matanya seperti petal lotus hitam. Jalannya anggun, dan dia suka tidur dan kehidupan yang nyaman. Meskipun dia mudah tersinggung, dia penuh kasih dengan suaminya. Kamanya harus seperti lotus.

Wanita kuda betina memiliki badan yang menawan dan jalannya yang anggun. Wajahnya dengan dahi agak rata serta mata dan mulutnya lebar. Memiliki leher yang panjang. Biasanya orang seperti ini biasanya penyayang. Orang seperti ini memiliki panjang yoni sekitar 9 jari.

The Karini has a Yoni twelve fingers in depth. Un clean in her person, she has large breasts; her nose, ears, and throat are long and thick; her cheeks are blown or expanded; her lips are long and bent outwards (bordes); her eyes are fierce and yellow-tinged; her face is broad; her hair is thick and somewhat blackish; her feet, hands, and arms are short and fat; and her teeth are large and sharp as a dog's. She is noisy when eating; her voice is hard and harsh; she is gluttonous in the extreme, and her joints crack with every movement. of a wicked and utterly shameless disposition, she never hesitates to commit sin. Excited and disquieted by carnal desires, she is not easily satisfied, and requires congress unusually protracted. Her Kama-salila is very abundant, and it suggests the juice which flows from the elephant's temples.

Katrini memiliki yoni dengan panjang 12 jari. Orangnya tidak bersih, memiliki payudara besar; hidung, telinga dan kerongkongannya panjang dan tebal; dagunya mengembang, bibirnya panjang dan melengkung keluar; matanya kuning, mukanya lebar; rambutnya tebal dan hitam; kaki, tangan, dan lengannya pendek dan gemuk; dan giginya lebar dan tajam seperti anjing. Dia rebut saat makan; suaranya keras dan bergema. Persendiannya pecah-pecah disetiap gerakannya. Penampilannya tidak tau malu, dia tidak ragu untuk melakukan dosa. Sangat tertarik dengan kenikmatan binatang, dia tidak mudah puas, dan menginginkan seks dengan tidak biasa. Kamanya berlimpah.

Tipe katrini memiliki ciri-ciri tubuh yang sangat gampang untuk dikenali. Menurut teks Ananga Ranga, kehidupan orang ini biasanya jorok, tidak memperhatikan kebersihan. Memiliki wajah yang agak sangat dengan hidung yang besar, telinga lebar dan leher yang besar, bibirnya panjang dan melengkung ke bawah. Kaki dan tangannya pendek dan gemuk. Biasanya secara umum wanita ini memiliki 
payudara besar. Ciri-ciri fisik seperti ini menandakan liang vaginanya sangat dalam. Hanya penis tertentu yang mampu mempenetrasinya. Dipastikan bahwa lingga yang pendek tidak akan bisa memuaskannya karena linganya yang dalam, menyebabkan letak G-spot juga dalam. Penis yang tidak mampu menyentuh titik G-spot tidak akan mampu memberikan rangsangan maksimal kepada pasangannya.

Melihat semua tipe itu, baik laki maupun perempuan, harus mampu menemukan tipe pasangannya dengan tepat. Perempuan yang memiliki kedalaman Yoni pendek mesti menemukan pasangan yang lingganya pendek pula, demikian sebaliknya. Jika wanita dengan liang pendek dimasuki oleh penis panjang akan sangat berbahaya. Hubungan seks ini tidak akan berakhir nikmat, melainkan cedera dari pihak wanita. Bagi laki-lakinya pun tidak akan merasa nyaman karena tidak bisa leluasa menekan lingga ke dalam. Begitu juga sebaliknya, jika Yoni yang dalam dimasuki lingga pendek juga tidak mampu memberikan kenikmatan maksimal. Wanita tidak maksimal merasakan yoninya dimasukin, demikian juga laki-laki tidak nyaman karena lingganya tidak banyak ditekan oleh liang yoni lawan mainnya. Ananga Ranga (Burton, 2001: 14-15) memberikan uraian secara detail dalam bentuk bagan bagaimana hubungan seks yang terjadi diantara mereka. Yang mana hubungan itu mampu mencapai kepuasan maksimal, dan mana yang tidak mampu mencapai klimaks maksimal.

\section{Tabel 4.1}

\section{Diperuntukkan laki-laki Shasha (kelinci)}

\begin{tabular}{|c|c|c|}
\hline Nama & Dimensi ukuran & Kategori \\
\hline $\begin{array}{c}\text { Shasha } \\
\text { Mrigi }\end{array}$ & 6 jari & Utama \\
\hline Shasha & 6 jari & \\
Ashvini & 9 jari & Madhyama \\
\hline Shasha & 6 jari & Kanishta \\
Katrini & 12 jari & \\
\hline
\end{tabular}

Berdasarkan table di atas dapat dikatakan bahwa laki-laki shasha (kelinci) jika berhubungan seks dengan perempuan mrigi (kijang) akan bisa maksimal, karena ukuran panjang penis dan kedalaman liang vagina sama-sama sekitar 6 jari. Jadi tidak ada masalah dengan hubungan ini. Kategori hubungan ini adalah utama, artinya mampu mencapai puncak kenikmatan. Sementara itu jika laki-laki shasha menerobos liang vagina wanita ashvini (kuda betina) termasuk kategori madhyama, artinya kenikmatan yang diraih sedang-sedang, tidak nikmat sekali, tidak pula buruk. Mungkin pada saat senggama, lingga laki-laki shasha sesekali mampu menyentuh titik G-spot wanita ashvini, sehingga kemungkinan si wanita mampu mencapai klimaks. Hubungan ini memerlukan sedikit usaha di dalam upaya memeroleh kepuasan.

Sementara itu hubungan seks yang buruk terjadi antara laki-laki shasha dengan wanita katrini (gajah). Laki-laki dengan ukuran penis 6 jari tidak akan mampu menembus liang wanita katrini sepenuhnya, sehingga kemungkinan titik nikmat wanita ini tidak mampu disentuhnya. Demikian juga wanita ini tidak bisa maksimal merasakan bahwa liangnya dimasuki oleh penis, sehingga sensasi yang dirasakan sangat kecil. Demikian juga bagi pihak laki tidak akan mendapat cengkraman kuat dari wanita katrini, sehingga ketika penetrasi penis tidak merasakan sensasi apa-apa. Hubungan ini semestinya dihindari jika ingin senggama itu mencapai kenikmatan maksimal.

Tabel 4.2

\section{Diperuntukkan bagi laki-laki Vrishabha (kerbau)}

\begin{tabular}{|c|c|c|}
\hline Nama & Dimensi ukuran & Kategori \\
\hline Vrishabha & 9 jari & Madhyama \\
Mrigi & 6 jari & \\
\hline Vrishabha & 9 jari & Utama \\
Ashvini & 9 jari & \\
\hline Vrishabha & 9 jari & Madhyama \\
Katrini & 12 jari & \\
\hline
\end{tabular}

Laki-laki kerbau dengan ukuran lingga sekitar 9 jari akan sangat ideal jika berhubungan seks dengan wanita kuda betina karena memiliki kedalaman liang vagina juga sekitar 9 jari. Pasangan ini akan mampu saling memberikan kabahagiaan karena secara ukuran seimbang. Yoni akan dengan mudah mewadahi lingga yang mendesaknya ke dalam tanpa masalah. Demikian juga lingga akan mendapat gesekan yang sesuai sehingga kenikmatan yang ditimbulkan semakin tinggi. Sementara itu laki- 
laki kerbau apabila berhubungan dengan wanita kijang akan mengalami kesusahan, karena jika sang kerbau menancapkan penuh lingganya, kemungkinan wanita akan mengalami kesakitan, karena dinding bagian dalam vagina di tekan keras. Disini, kemampuan laki-laki untuk memahami kondisi ini sangat diperlukan, yakni dengan tidak memasukkan seluruh pusaka ke liang lawannya. Senggama dengan beberapa gaya yang menjadikan lingga tidak masuk sepenuhnya akan sangat bagus. Namun, menurut teks di atas, secara keseluruhan, kenikmatan seksual yang dihadirkan tidak maksimal, karena ada salah satu dari mereka yang tidak sepenuhnya mengekspresikan nafsu seksualnya. Laki-laki harus mengguakan pikirannya saat itu untuk mampu mengontrol agar kondisi coitus berjalan normal. Penggunaan pikiran terlalu banyak dalam hubungan seks tidak menghasilkan kenikmatan yang maksimal. Hubungan seks adalah sharing rasa dan sara hanya ada dalam totalitas.

Demikian juga laki-laki kerbau berhubungan dengan wanita gajah, dia harus terus berusaha agar lingganya mampu menyentuh G-spot lawannya secara teratur. Dia harus mampu mengatur gaya hubungan sehingga tetap memungkinkan batang lingganya bisa sepenuhnya masuk ke liang. Dengan ini hubungan tersebut mampu mencapai kenikmatan. Hanya saja, hubungan ini juga menggunakan banyak pikiran dan mengurangi totalitasnya. Belum lagi pihak wanita tidak maksimal merasakan dinding liang vagina mencengkeram lingga yang menerobos masuk. Jika pihak wanita tidak kooperatif, hubungan ini menjadi tidak nyaman.

Tabel 4.3

\section{Diperuntukkan bagi laki-laki Ashva (kuda)}

\begin{tabular}{|c|c|c|}
\hline Nama & Dimensi ukuran & Kategori \\
\hline Ashva & 12 jari & Kanishta \\
Mrigi & 6 jari & \\
\hline Ashva & 12 jari & Madhyama \\
Ashvini & 9 jari & \\
\hline Ashva & 12 jari & Utama \\
Katrini & 12 jari & \\
\hline
\end{tabular}

Laki-laki kuda memiliki panjang penis sekitar 12 jari. Agar hubungan seks yang terjad berimbang, maka ia harus mencari pasangan wanita tipe gajah. Hubungan antara laki kuda dan wanita gajah sangat serasi dan saling memberikan kepuasan. Tidak akan ada halangan apapun diantara mereka. Liang yang panjang diterobos oleh lingga yang panjang juga sangat menyenangkan. Sensasi yang dihasilkan dari hubungan kedua jenis ini adalah utama. Tetapi jika laki-laki kuda berhubungan dengan wanita Ashvini agak sedikit masalah, sebab liangnya tidak cukup panjang untuk menampung desakan lingga laki kuda. Namun, jika laki kuda agak sedikit bersabar, mau mengendorkan sedikit desakannya agar lingganya tidak masuk semua, hubungan ini akan mampu menghasilkan kenikmatan maksimal, terutama bagi pihak wanita. Hanya saja bagi laki-laki agak sedikit menggunakan pikiran, karena harus mengontrol kendalinya ketika dalam pertempuran.

Hubungan yang paling buruk adalah antara laki kuda dan wanita kijang. Hubungan ini kalau bisa dihindari karena menimbulkan ketidaknyamanan bagi wanita. Lingga laki kuda terlalu panjang untuk ukuran wanita kijang, sehingga jika dipaksakan tidak terttup kemungkinan terjadi cedera. Kedua belah pihak tidak akan nyaman, sebab laki-laki tidak akan bisa mempenetrasi wanitanya secara sempurna, demikian juga wanita tidak mampu menampung lingga lakinya dengan baik. Bagi mereka yang skill di dalam bercinta, hubungan jenis pasangan ini hendaknya dihindari. Apalagi mereka yang memutuskan untuk menjadi suami dan istri, ketidaknyamanan yang terus-menerus dalam hubungan seksual akan berdampak buruk bagi mereka.

\section{PENUTUP}

Menurut teks Paururava Manasija Sutra dan beberapa teks kama lainnya bahwa melakukan teknik pendahuluan sangat dianjurkan dalam hubungan seksual. Dari berbagai jenis pendahuluan, teknik ciuman sangat dianjurkan. Ciuman adalah saah satu bagian awalan hubungan seksual yang membuat kedua pasangat tersulut nafsnya. Melalui ciuman, birahi kedua orang berbeda jenis kelamin tersebut tersulut dan semakin bergairah untuk segera melakukan penetrasi. Pada saat melakukan ciuman, beberapa teknik lainnya juga sangat disarankan dilakukan secara bersamaan. Teks Paururava menekankan 
tentang pentingnya bermain pada payudara perempuan yang diajak. Seorang perempuan memerlukan durasi waktu yang lebih panjang agar tubuhnya siap diajak bersenggama. Bermain di areal payudara merupakan cara yang paling tepat agar gairah wanita memuncak. Ketika perempuan sudah panas, maka penetrasi ke dalam liangnya akan membuat pikiran melayang.

Demikian juga dalam beberapa teks kama lainnya, guna memaksimalkan kenikmatan yang dihasilkan dalam sebuah sanggama, memiliki jenis pasangan yang tepat sangat dianjurkan. Menurut teks, ada tiga jenis laki-laki menurut panjang kelaminnya, yakni Shasha (kelinci), Vrishabha (kerbau), dan Ashwa (kuda). Shasha berukuran sekitar 6 jari, Vrishabha 9 jari dan Ashva 12 jari. Demikian juga perempuan dibagi menjadi tiga jenis, berdasarkan pada kedalaman dan keluasan Yoni. Mereka adalah Mrigi atau Harini (perempuan kijang), Vadava atau Ashvini (kuda Betina), dan Karini (perempuan gajah). Mrigi panjangnya kedalamannya 6 jari, Ashvini 9 jari dan Karini 12 jari. Jika ukuran laki-laki pendek sementara kedalaman panjang akan menyebabkan ketidakpuasan seperti misalnya laki-laki shashatidakakan baikjika berhubungan dengan perempuan Karini. Hubungan itu akan menghasilkan kenikmatan maksimal hanya ketika panjang kelamin laki-laki sejajar dengan kedalaman yoni perempuan.

\section{DAFTAR PUSTAKA}

Burton, Sir Richard. 2001. The Ananga Ranga. Blackmask Online.

Iyengar, B.K.S, 2002. Light on the Yoga Sutra of Patanjali. Great Britain: Thorsons.

Kamala Devi. 1977. The Eastern Way of Love. Simon \& Schuster.

Omar Garrison. 1964. Tantra: the Yoga of Sex. Causeway Books.

Olivelle, tr. 1996. Upanisads. Oxford New York: Oxford University Press.

Osho, 1973. Yoga: The Alpa and the Omega, Vol.1: Book PDF Series. 